Supporting Information for:

\title{
Synthesis and Surface Chemistry of Cadmium Carboxylate Passivated CdTe Nanocrystals from Cadmium bis(phenyltellurolate)
}

\author{
Michael P. Campos and Jonathan S. Owen* \\ Department of Chemistry, Columbia University in the City of New York \\ New York, New York 10027, United States \\ Email: jso2115@columbia.edu
}




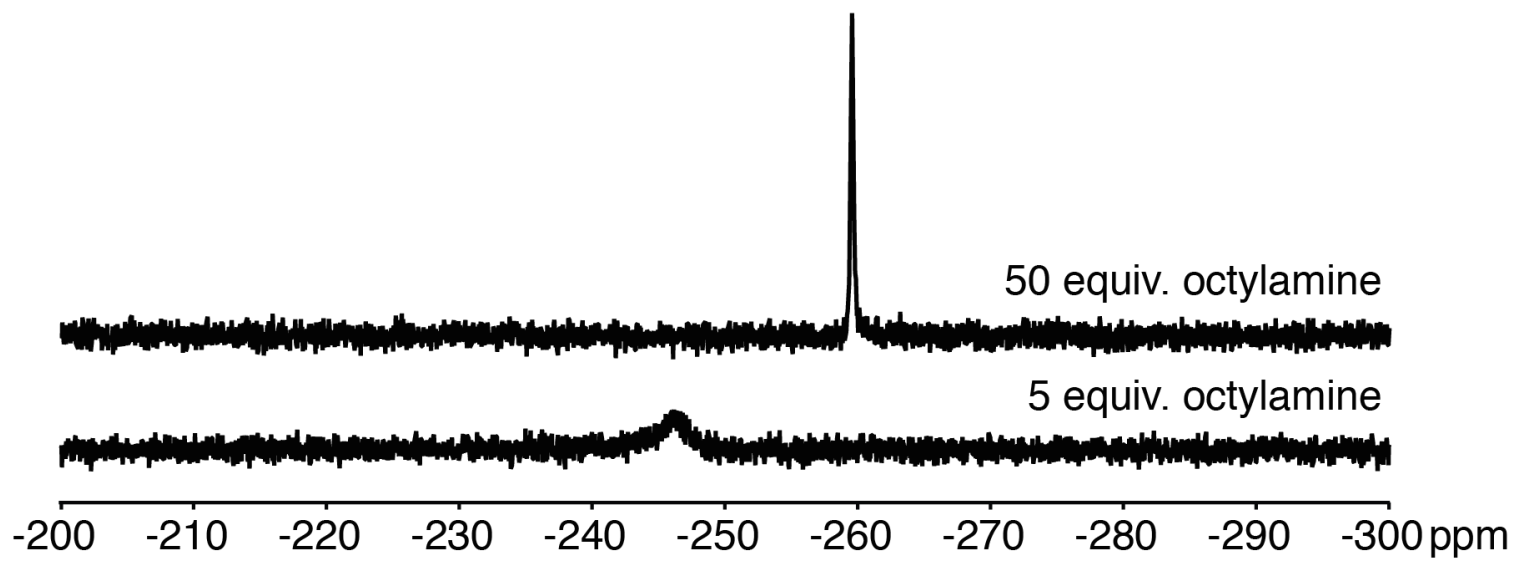

Figure S1. ${ }^{125} \mathrm{Te}$ NMR spectra of $\mathrm{Cd}(\mathrm{TePh})_{2}$ in benzene- $d_{6}$ upon addition of 5 and 50 equivalents of $n$-octylamine.

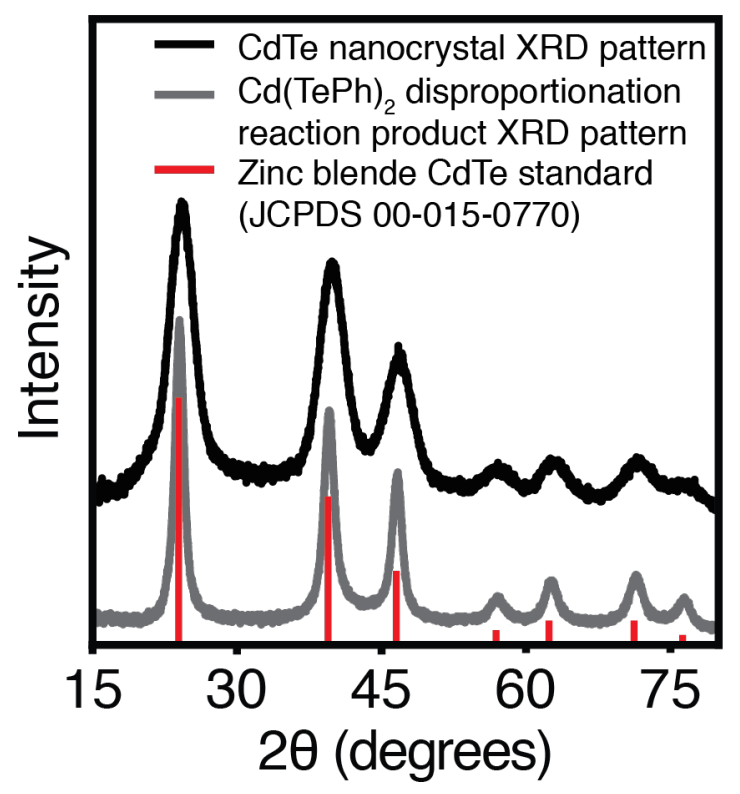

Figure S2. Powder X-ray diffraction pattern of CdTe nanocrystals (black) and polycrystalline CdTe produced by disproportionation of $\mathrm{Cd}(\mathrm{TePh})_{2}$ at $220{ }^{\circ} \mathrm{C}$ in hexadecane (gray). Exponential baseline corrections were applied to the data to remove signal from scattering. The CdTe standard (red) was obtained from the Joint Committee on Powder Diffraction Standards (JCPDS) as coll. code 00-015-0770. 

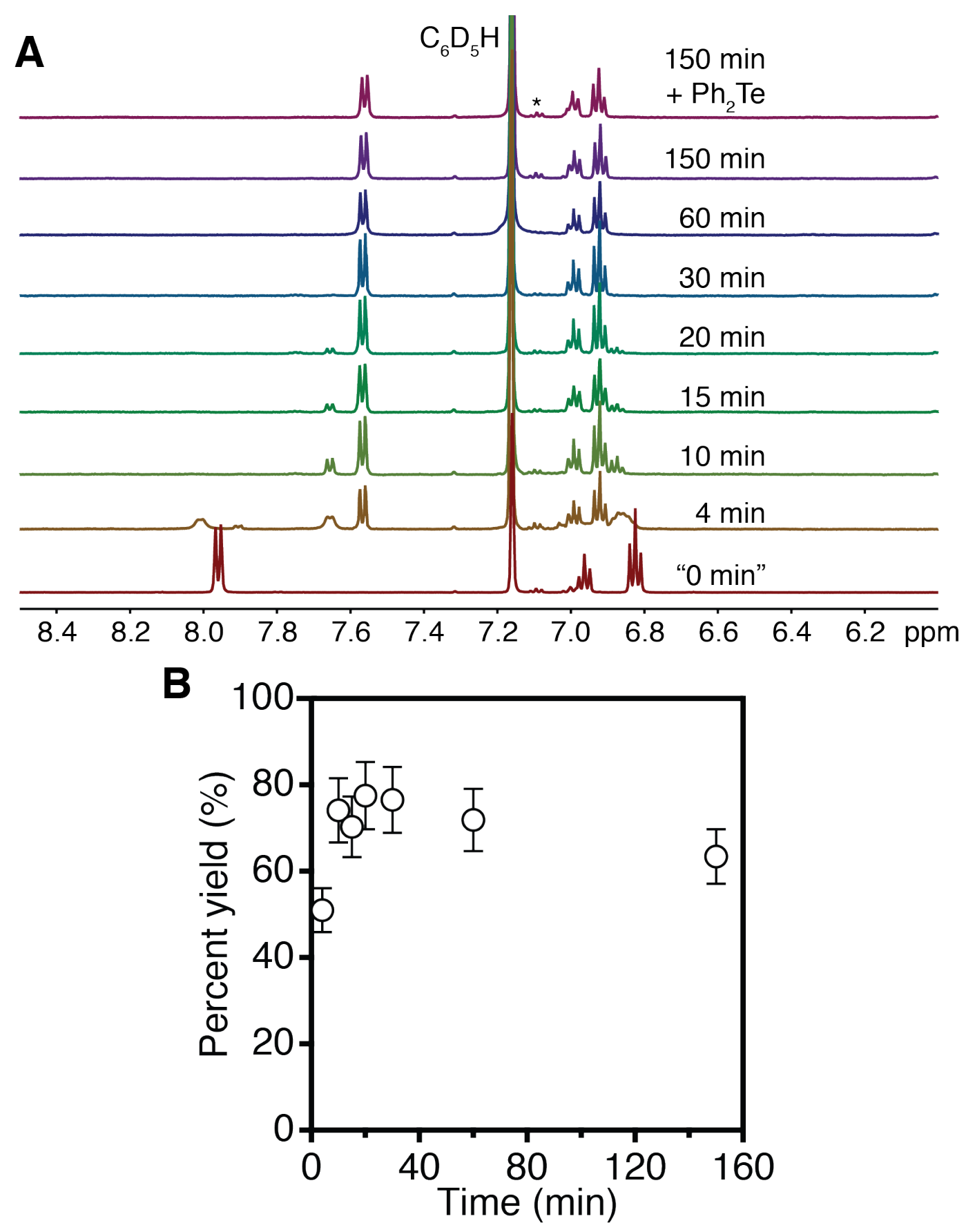

Figure S3. A) ${ }^{1} \mathrm{H}$ NMR spectra of crude reaction mixture ("0 min"), aliquots removed during synthesis (4 min - $150 \mathrm{~min}$ ), and the final aliquot with added diphenyl telluride prepared by the thermolysis of $\mathrm{Cd}(\mathrm{TePh})_{2}$ in hexadecane $\left(150 \mathrm{~min}+\mathrm{Ph}_{2} \mathrm{Te}\right)$. $\left(^{*}\right)$ denotes a toluene impurity. Additional signals in the $t=4-20 \mathrm{~min}$. aliquots may result from a complex between cadmium oleate and the diphenyl telluride, or a monocarboxylatemonotellurolate cadmium complex that results from comproportionation of the precursors. B) $\mathrm{Ph}_{2} \mathrm{Te}$ yield as measured by ${ }^{1} \mathrm{H}$ NMR. 


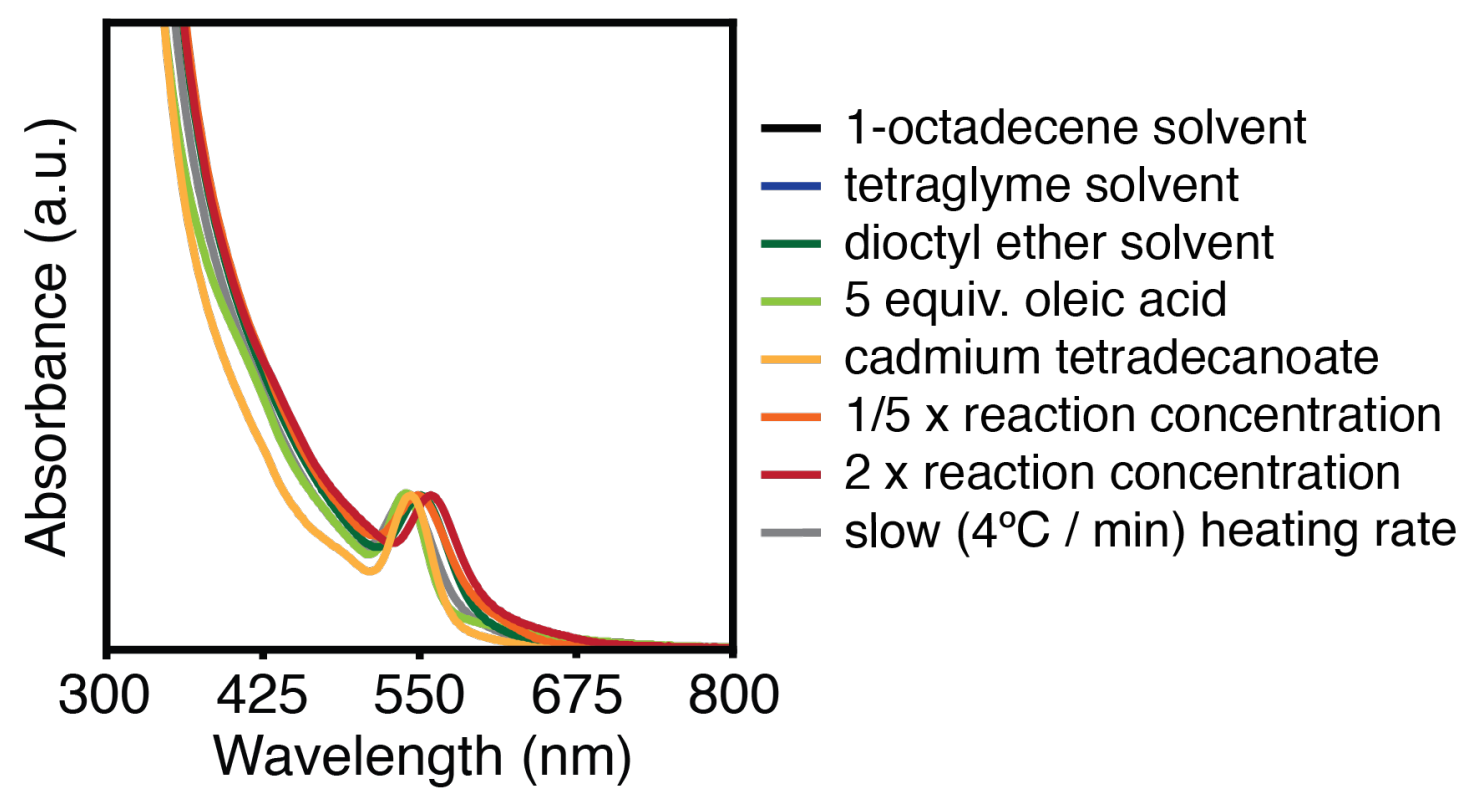

Figure S4. Absorbance spectra showing insensitivity of the final nanocrystal size to synthesis conditions. Spectra are normalized to the height of the excitonic band.
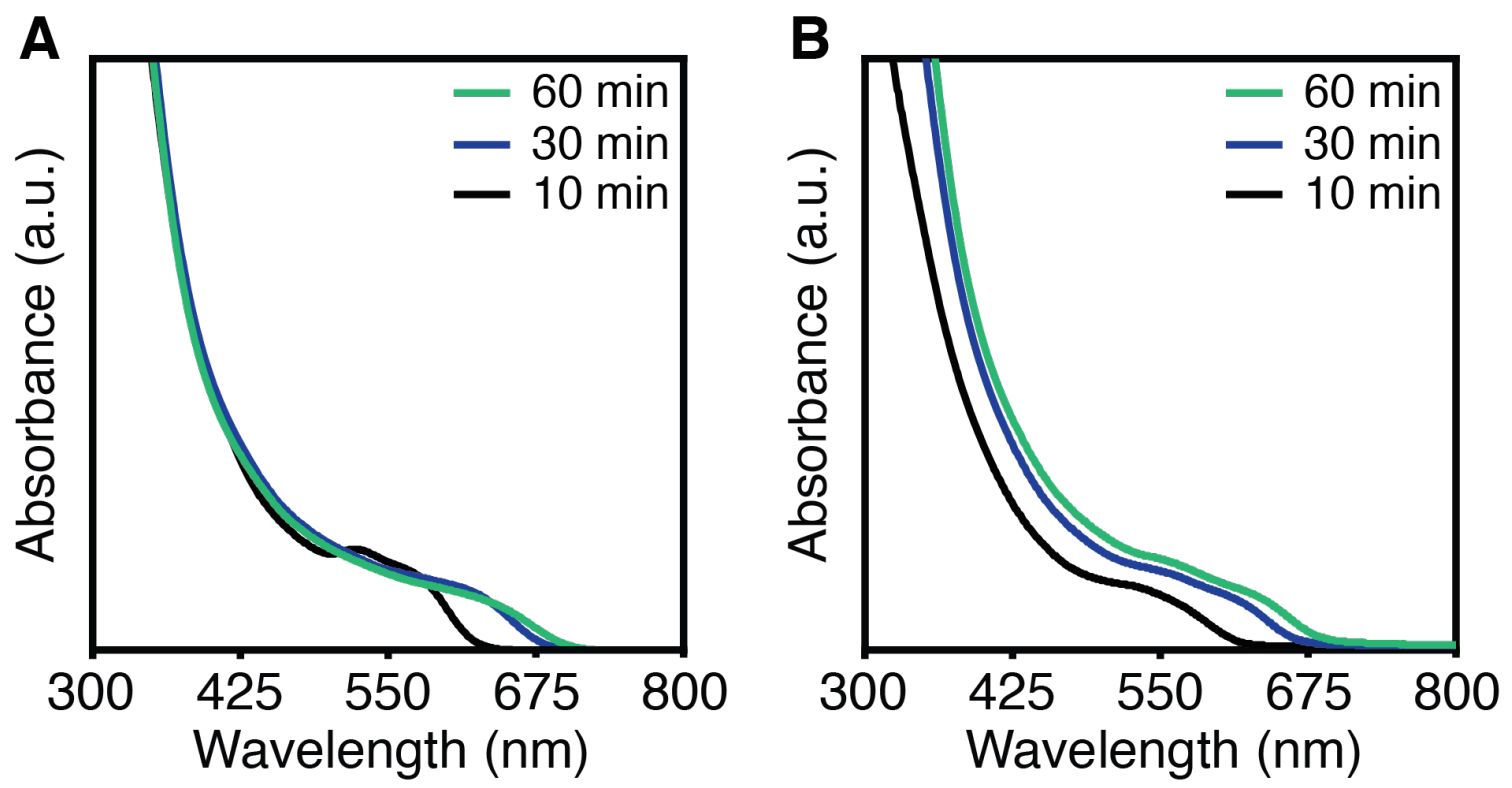

Figure S5. UV-visible absorbance spectra of nanocrystal synthesis reactions run in the presence of 5 equivalents of $A$ ) tributylphosphine and $B$ ) octadecylamine. 


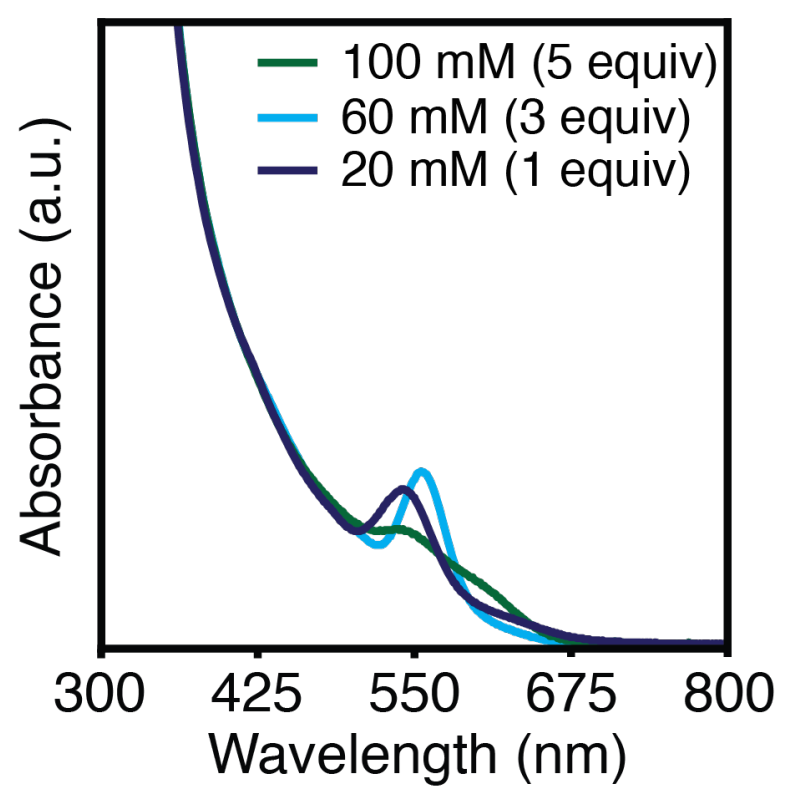

Figure S6. UV-visible absorbance spectra of nanocrystal synthesis reactions run in the presence of $\mathrm{A}$ ) one, $\mathrm{B}$ ) three, and C) five equivalents of cadmium oleate. Spectra are normalized to the absorbance at $410 \mathrm{~nm}$. 


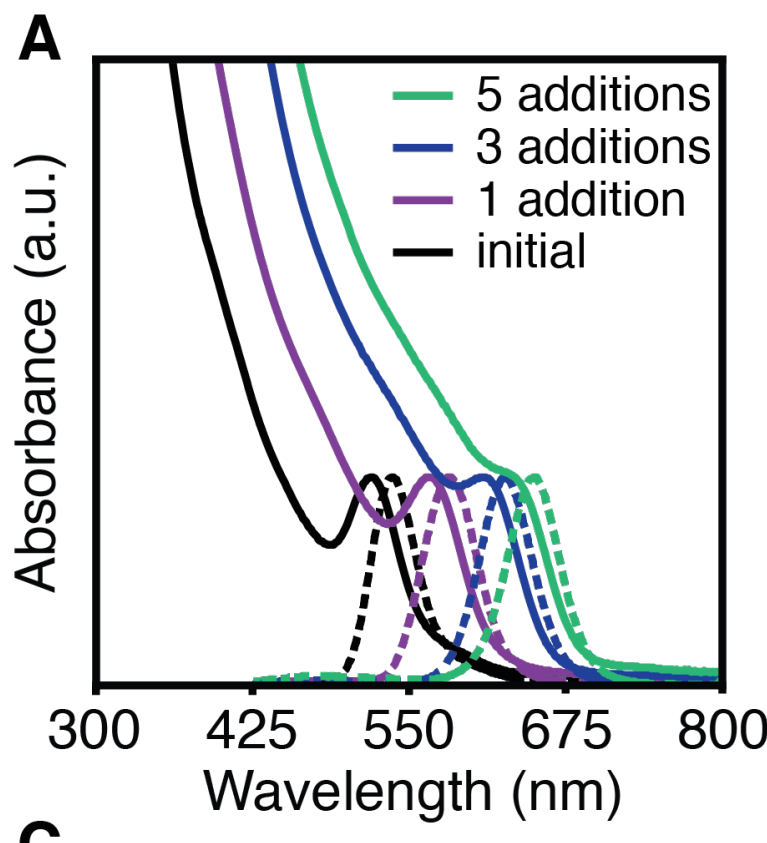

B

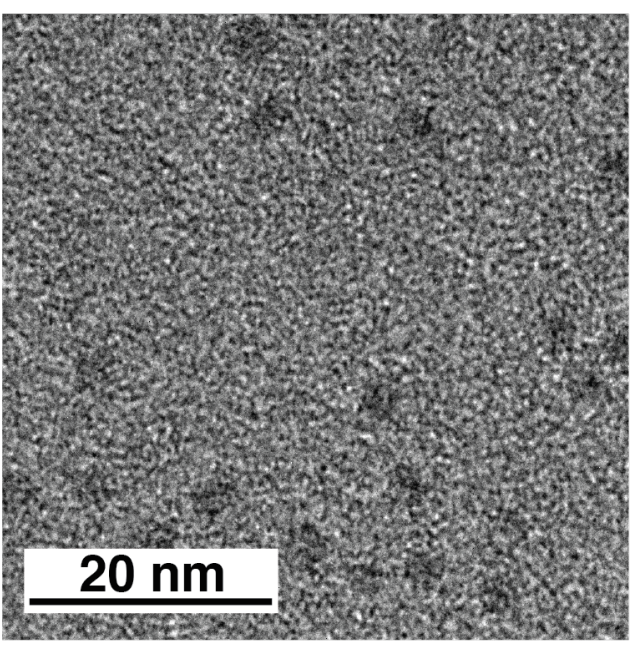

$\mathbf{C}$

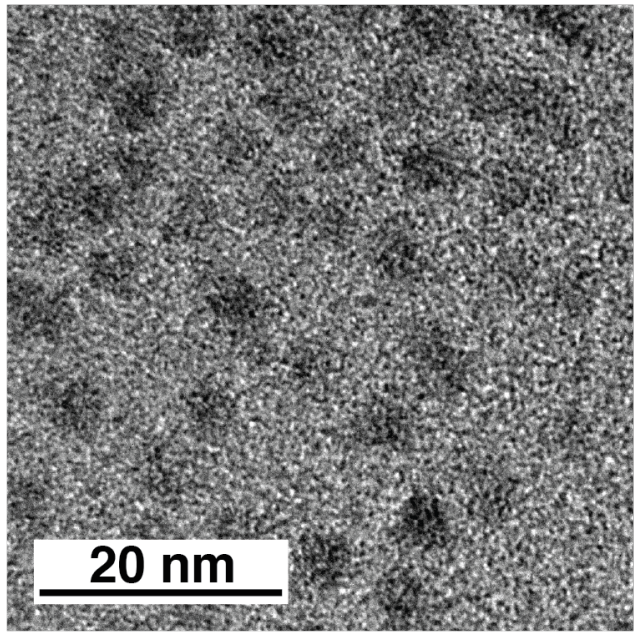

D

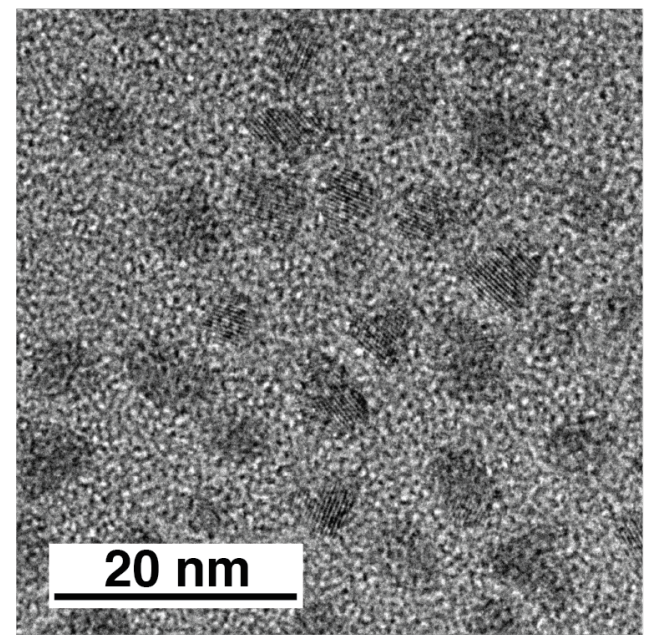

Figure S7. A) Absorbance and photoluminescence spectra of CdTe nanocrystals grown by successive additions of precursor mixture to a synthesis mixture at completion. Transmission electron micrographs of CdTe nanocrystals after A) one, B) three, and C) five additions of precursor mixture. 


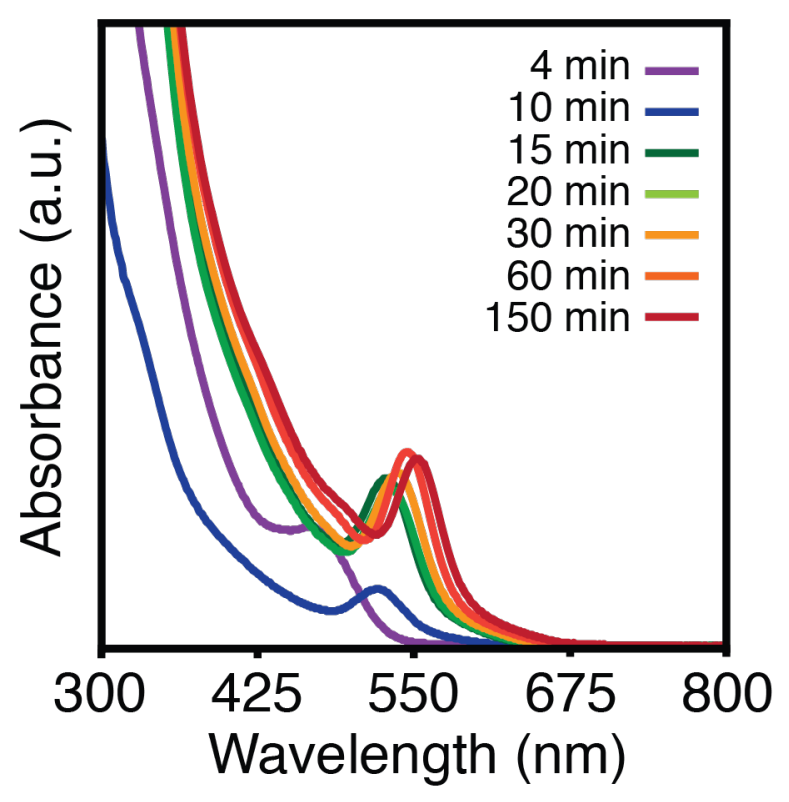

Figure S8. UV-vis absorbance spectra of aliquots removed from a nanocrystal kinetics reaction (4 $\mathrm{min}-150 \mathrm{~min})$.

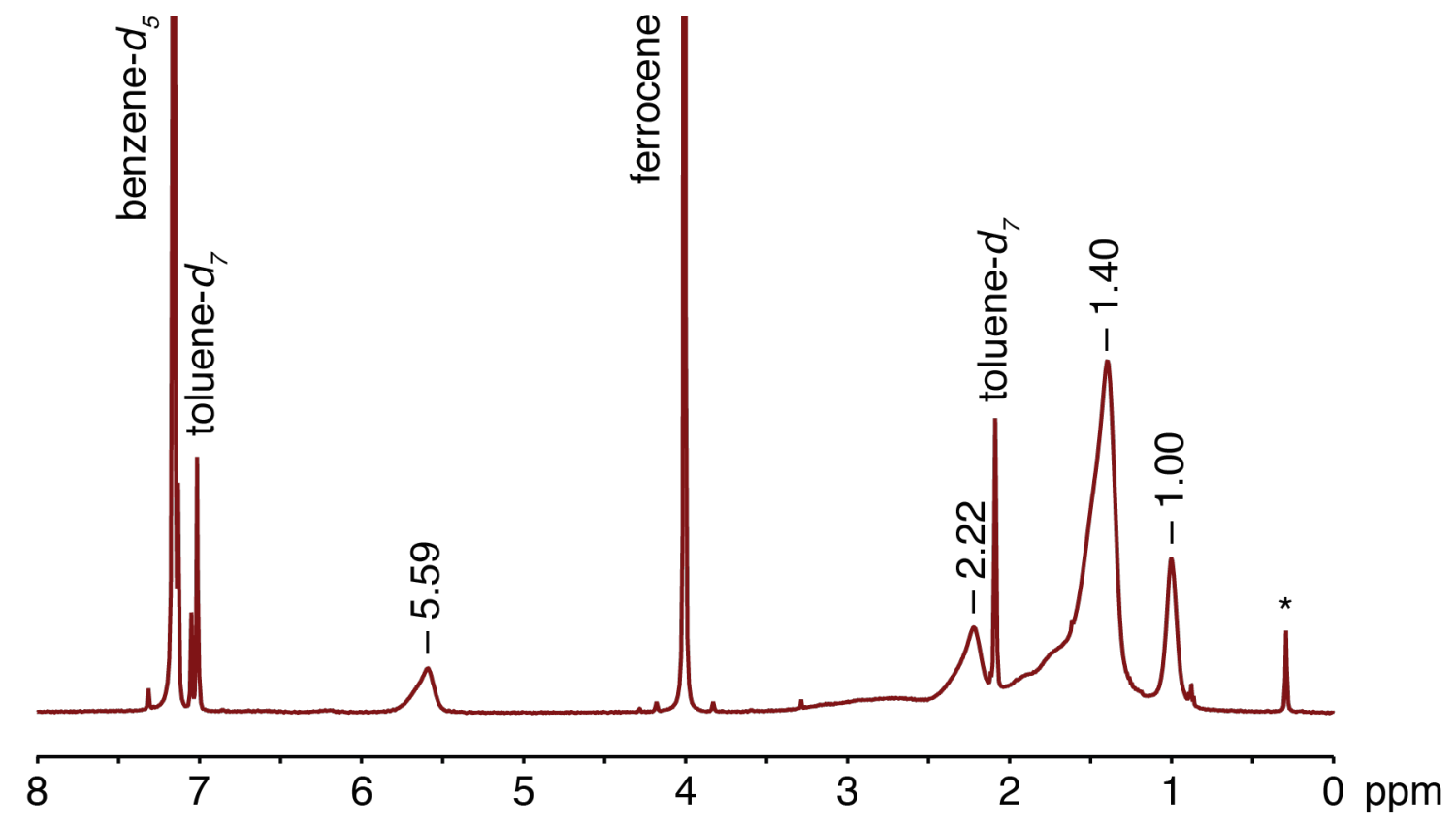

Figure S9. ${ }^{1} \mathrm{H}$ NMR spectrum of CdTe nanocrystals dissolved in benzene- $d_{6}$ with addition of a ferrocene internal standard dissolved in toluene- $d_{8 .}\left(^{*}\right)$ denotes a small silicone impurity leached from the silicone liner of the vial caps. 


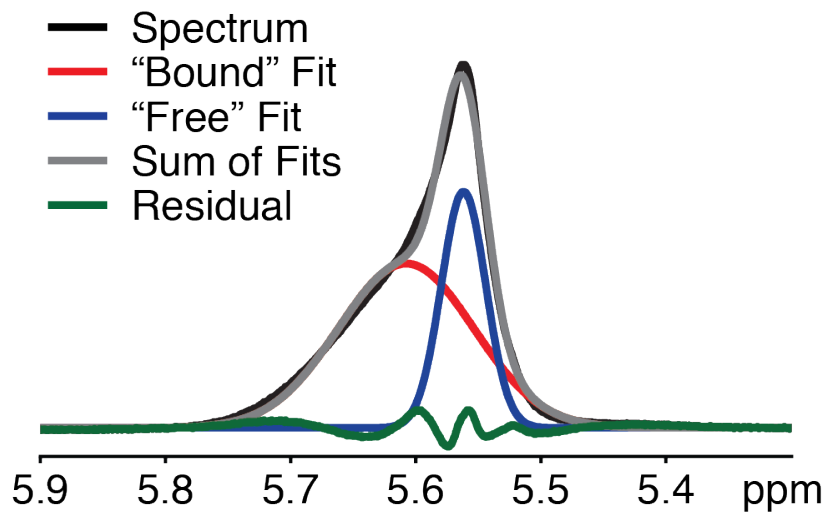

Figure S10. Vinyl region of ${ }^{1} \mathrm{H}$ NMR spectrum of CdTe nanocrystals with 4.7 oleates $/ \mathrm{nm}^{2}$ shown in Figure 3B with an approximate fit to two Gaussians. The broad downfield peak represents surface-bound cadmium oleate $(67.9 \%$ of total signal) and the sharper upfield peak represents free cadmium oleate (32.1\% of total signal). This analysis reduces the measured surface coverage to 3.1 oleates $/ \mathrm{nm}^{2}$.

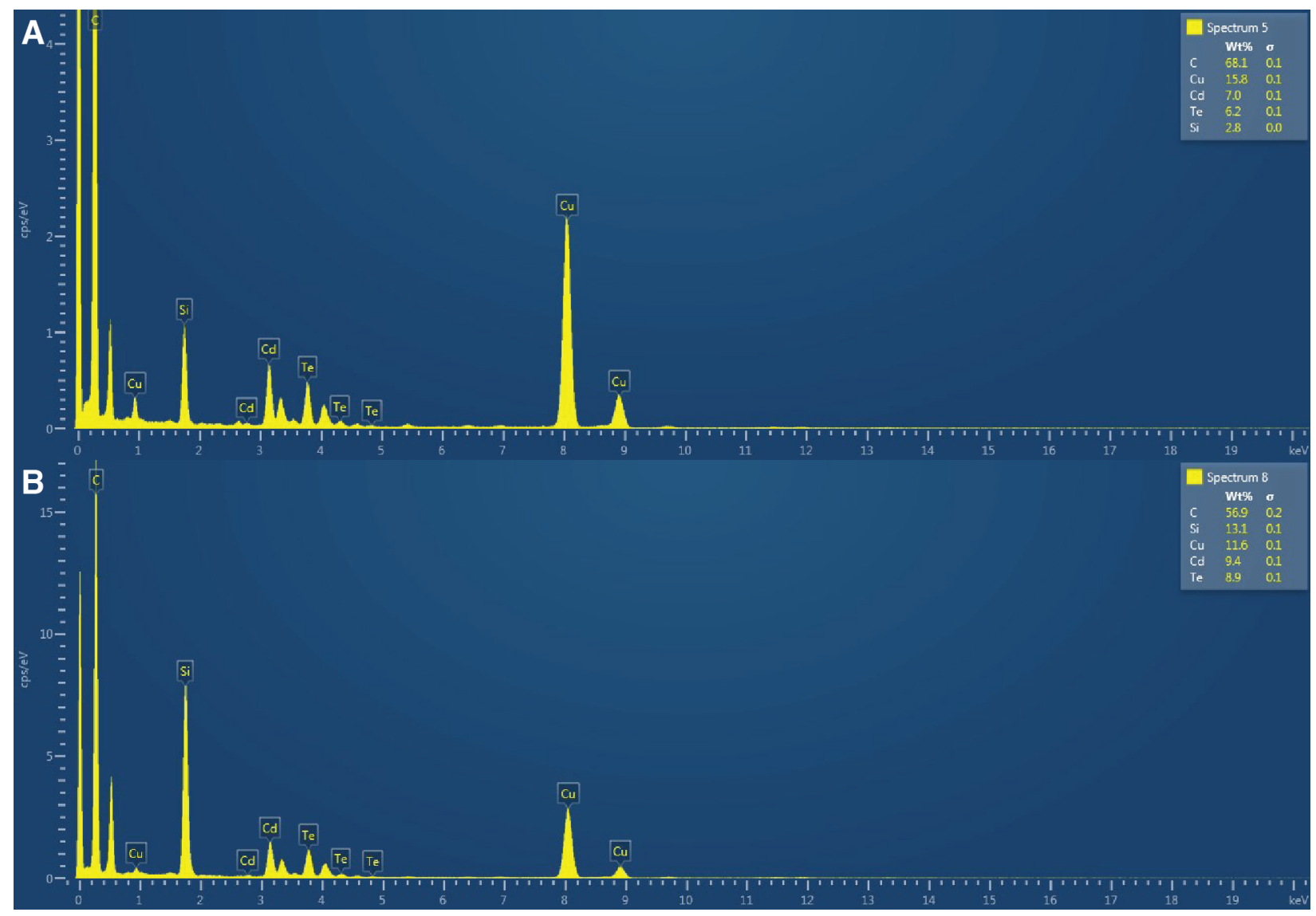

Figure S11. Energy-dispersive X-ray spectra of CdTe nanocrystal samples with A) 3.1 carboxylates $/ \mathrm{nm}^{2}$ and B) 2.3 carboxylates $/ \mathrm{nm}^{2}$. 
Table S1. Crystal, intensity collection, and refinement data for (TMEDA)Cd(TePh) ${ }_{2}$ shown in Figure 1.

\begin{tabular}{|c|c|}
\hline Crystal size & $0.480 \times 0.200 \times 0.80 \mathrm{~mm}$ \\
\hline Lattice & Monoclinic \\
\hline Formula & $\mathrm{C}_{18} \mathrm{H}_{26} \mathrm{CdN}_{2} \mathrm{Te}_{2}$ \\
\hline Formula weight & 638.01 \\
\hline Space group & $\mathrm{P} 2(1) / \mathrm{c}$ \\
\hline$a(\AA)$ & 13.0754(8) \\
\hline$b(\AA)$ & $11.4619(7)$ \\
\hline$c(\AA)$ & $15.1442(10)$ \\
\hline a (deg.) & 90 \\
\hline$\beta$ (deg.) & $112.3765(8)$ \\
\hline Y (deg.) & 90 \\
\hline$V\left(\AA^{3}\right)$ & $2098.7(2)$ \\
\hline Z & 4 \\
\hline Temperature (K) & $130(2)$ \\
\hline Radiation $(\lambda, \AA ̊)$ & 0.71073 \\
\hline$\rho$ (calcd.) $\left(\mathrm{g} / \mathrm{cm}^{3}\right)$ & 2.019 \\
\hline$\mu(\mathrm{Mo} \mathrm{Ka})\left(\mathrm{mm}^{-1}\right)$ & 3.767 \\
\hline$\Theta \max$ (deg.) & 33.004 \\
\hline No. of data collected & 36600 \\
\hline No. of data & 7586 \\
\hline No. of parameters & 212 \\
\hline $\mathrm{R}_{1}[I>2 \sigma(I)]$ & 0.0184 \\
\hline$\omega \mathrm{R}_{2}[I>2 \sigma(I)]$ & 0.0424 \\
\hline $\mathrm{R}_{1}$ [all data] & 0.0206 \\
\hline$\omega \mathrm{R}_{2}$ [all data] & 0.0432 \\
\hline GOF & 1.105 \\
\hline
\end{tabular}


Table S2. Cadmium-to-tellurium ratios in CdTe samples as measured by ${ }^{1} \mathrm{H}$ NMR/UVvisible analysis of ligand-to-semiconductor ratios and energy-dispersive X-ray spectroscopy (EDX).

$\begin{array}{cccc}\text { Sample } & \begin{array}{c}\text { Carboxylate } \\ \text { coverage }\left(\mathrm{nm}^{-2}\right)\end{array} & \begin{array}{c}\text { Cd:Te ratio by } \\ \text { NMR/UV-vis }\end{array} & \begin{array}{c}\text { Cd:Te ratio by } \\ \text { EDX }\end{array} \\ 1 & 3.7 & 1.25 \pm 0.13 & - \\ 2 & 3.0 & 1.19 \pm 0.12 & 1.28 \pm 0.03 \\ 3 & 2.9 & 1.19 \pm 0.12 & - \\ 4 & 2.6 & 1.17 \pm 0.12 & - \\ 5 & 2.3 & 1.15 \pm 0.12 & 1.20 \pm 0.02\end{array}$

Table S3. Surface site and ligand density values calculated for $\mathrm{Cd}\left(\mathrm{O}_{2} \mathrm{CR}\right)_{2}$-bound $\mathrm{CdSe}$ and CdTe nanocrystals. CdSe nanocrystal data is obtained from reference 29 in the main text. Lattice constants are obtained from the Joint Committee on Powder Diffraction Standards (JCPDS) as coll. codes 00-019-0191 (CdSe) and 00-015-0770 (CdTe) and atom densities are calculated geometrically from the zinc blende unit cell.

$\begin{array}{ccc}\text { Nanocrystal sample } & \text { CdSe } & \text { CdTe } \\ \text { Zinc blende lattice constant }(\mathrm{nm}) & 0.6077 & 0.6481 \\ \text { Atom density on }\{100\} \text { facet }\left(\mathrm{nm}^{-2}\right) & 5.42 & 4.76 \\ \text { Atom density on }\{111\} \text { facets }\left(\mathrm{nm}^{-2}\right) & 6.25 & 5.50 \\ \text { Average surface atom density }\left(\mathrm{nm}^{-2}\right) & 5.83 & 5.13 \\ \text { Average surface chalcogen density }\left(\mathrm{nm}^{-2}\right) & 2.92 & 2.56 \\ & & \\ \text { Peak position }(\mathrm{nm}) & 571 & 552 \\ \text { Peak position }(\mathrm{eV}) & 2.17 & 2.25 \\ \text { Average nanocrystal diameter }(\mathrm{nm}) & 3.57 & 3.25 \\ \text { Surface area per nanocrystal }\left(\mathrm{nm}^{2}\right) & 39.9 & 33.2 \\ \text { Surface chalcogen sites per nanocrystal } & 116.5 & 85.0 \\ \text { Cd }\left(\mathrm{O}_{2} \mathrm{CR}\right)_{2} \text { per nanocrystal after isolation } & 64.5 & 50.7 \\ \text { Carboxylate ligand density }\left(\mathrm{nm}^{-2}\right) & 3.3 & 3.1 \\ \text { Percent of surface chalcogen sites occupied } & 55.4 \% & 59.6 \%\end{array}$


Table S4. Electronic properties of cadmium chalcogenide semiconductors relevant to ionic/covalent character. ${ }^{1}$ In addition to large differences in electronegativity, strong ionic character manifests in small static and optical dielectric constants $\left(\varepsilon_{0}, \varepsilon_{\infty}\right.$, respectively; relative to the dielectric constant of vacuum). ${ }^{2}$

$\begin{array}{cccc}\text { Material } & \text { CdS } & \text { CdSe } & \text { CdTe } \\ \text { Pauling electronegativity difference } & 0.89 & 0.86 & 0.41 \\ \text { Dielectric constant }\left(\varepsilon_{0} / \varepsilon_{\infty}\right) & 8.28 / 5.23 & 9.3 / 6.2 & 10.4 / 7.1\end{array}$




\section{References}

(1) He, B.; Zhang, W. II-VI Semiconductors and Their Device Applications. In Handbook of Chalcogen Chemistry: New Perspectives in Sulfur, Selenium and Tellurium; Devillanova, F. A.; Mont, du, W.-W., Eds.; Royal Society of Chemistry: Cambridge, 2013; Vol. 2, pp. 180-231.

(2) R Heath, J. Covalency in Semiconductor Quantum Dots. Chem. Soc. Rev. 1998, $27,65-71$. 